\title{
A luta contra a homof obia: das condições de constituição dos movimentos homossexual e LGBTTT em Sergipe
}

Patrícia Rosalba Salvador Moura Costa ${ }^{1}$

Marcos Ribeiro de Melo ${ }^{2}$

Este artigo objetiva pontuar algumas características que marcaram a institucionalização dos movimentos Homossexual e LGBTTT no Estado de Sergipe, buscando-se estabelecer um elo entre as pautas de luta do movimento e a construção de políticas públicas no combate a homofobia. A metodologia usada está baseada na análise teórica no campo de estudos dos gêneros e sexualidades, os dados foram aferidos através de pesquisa documental e entrevistas. Os resultados mostram que os movimentos homossexuais e LGBTTT desenvolveram importantes mobilizações no Estado sergipano em torno das causas homossexuais. Os pontos fortes de luta incluíam o combate à violência contra homossexuais, a exigência de políticas públicas de prevenção à AIDS, e a luta incessante em prol do respeito à diversidade.

Palavras- Chave: movimento homossexual, homofobia, violências, sexualidades.

1 Doutora em Ciências Humanas, professora do Campus Aracaju- Instituto Federal de Sergipe, IFS. E-mail: patriciarosalba@gmail.com;

2 Doutor em Sociologia, professor adjunto do Departamento de Educação (UFS/Campus Itabaiana). E-mail: marcos_demelo@hotmail.com 


\title{
The struggle against homophobia: constitution of the conditions of gay and Igbttt movements in sergipe
}

\begin{abstract}
:
This article aims to expose some features that marked the institutionalization of Gay and LGBTTT movements in Sergipe, seeking to establish a link between the movement fight in guide lines and the construction of public policies against homophobia. The methodology used is based on the theoretical analysis in the field of studies of gender and sexuality, the data were measured through desk research and interviews. The results show that the homosexual movement and LGBTTT developed important mobilizations in the Sergipe State around gay causes. Strengths included the struggle against violence against homosexuals, the requirement of public policies for the prevention of AIDS and incessant struggle for respect to the diversity.
\end{abstract}

Key-words: Gay movement, homophobia, violence, sexualities.

\section{Introdução}

Na mídia, nas redes sociais, nas diferentes esferas políticas, nas universidades e nos eventos científicos, o termo homofobia ${ }^{3} \mathrm{e}$ suas atuais derivações são recorrentes e geram muitos debates sobre os vários tipos de violência aos quais a população LGBTTT tem sido submetida. 0 frequente uso da categoria, contudo, naturaliza e obscurece sua própria invenção e toda trama política,

3 Por se tratar de um artigo cujo principal objetivo é o de entender o processo histórico-social de constituição do combate à homofobia, privilegia-se este termo em detrimento de outros mais recentemente constituídos como lesbofobia, transfobia e bifobia, que expressam as lutas políticas e as idiossincrasias dos segmentos da população LGBT. 
dos movimentos sociais e do Estado, a partir da qual foi possível forjar e institucionalizar esta terminologia.

Assim como nem sempre o personagem homossexual existiu, pode-se afirmar que, do ponto de vista histórico, apenas recentemente, há cerca de vinte anos, a homofobia tem feito parte, de forma mais consistente, dos discursos e da gramática da mobilização LGBTTT brasileira. Diante do exposto, este artigo intenta compreender as condições de constituição do combate à homofobia em Sergipe, a partir das seguintes questões: como foi forjada esta bandeira? Que agentes estiveram envolvidos neste processo? Como o Estado participou da construção desta luta?

Para este fim foram realizadas entrevistas com lideranças do movimento envolvidas com o combate à homofobia e análises documentais que possibilitaram a construção de uma cronologia espaço-temporal do movimento (CASTRO, 2008) e das redes que configuram o surgimento de lutas em defesa dos direitos LGBTTT. 0 leitor encontrará o artigo dividido basicamente em dois momentos. No primeiro há um levantamento sobre o estado da arte e, no segundo instante, o debate se verticaliza em torno da realidade sergipana.

\section{C ontribuições dos M ovimentos H omossexual e LG BT T T para a luta contra homofobia}

Entender a importância que o Movimento Homossexual e LGBT$\mathrm{TT}^{4}$ tiveram para a constituição da categoria política homofobia requer que seja feito, inicialmente, um percurso sobre os estudos teóricos no campo das sexualidades. Nesta parte do artigo faz-se uso da reflexão teórica em torno das sexualidades através dos estudos de Foucault (1977; 1988), especialmente, com

4 Usa-se em todo o texto os termos movimento homossexual e movimento LGBTTT, pois retratam períodos históricos distintos a que este artigo faz referência. 
o objetivo de compreender como as sexualidades são postas em discursos.

Técnicas disciplinares que visavam o efetivo controle da sexualidade se desenvolveram a partir do século XIX, traduzidas por uma "vontade de saber" cujo objetivo era construir uma linguagem específica. 0 surgimento de uma ciência da sexualidade passou a regular e disciplinar o comportamento dos indivíduos a partir da definição do que é "normal" e "anormal”. Foucault, em sua clássica obra sobre a História da Sexualidade I, argumenta que a partir do final do século XVIII, o sexo começou a ser colocado em discurso, sendo submetido a um processo de intensa incitação, ao mesmo tempo em que as técnicas de poder obedeceram a um princípio de disseminação e implantação das sexualidades polimorfas, contribuindo para uma vontade de saber que se obstinou em construir uma ciência da sexualidade.

Apesar de instituída uma economia restritiva em relação ao sexo, é evidente também que a explosão discursiva em torno desse, nos últimos séculos, aumentou consideravelmente. Essa multiplicação dos discursos teve seu ápice no próprio campo de exercício de poder, ou seja, houve uma maior incitação a se falar e ouvir cada vez mais institucionalmente sobre o sexo, criando-se um dispositivo "completo e de efeitos variados" (FOUCAULT, 1988, p. 29), contribuindo para o surgimento no século XVIII de uma vontade política, econômica, estatística, contabilista, classificatória e analítica para falar do sexo com base em pressupostos racionais.

A disseminação de múltiplos discursos úteis e públicos cumpre o objetivo de policiar, explicar, esconder e racionalizar o sexo. Falar, ouvir, observar, interrogar, registrar e acumular boas quantidades de discursos e explicações sobre o sexo faz parte de um projeto de controle da sexualidade pensado e praticado de forma mais intensa pela sociedade ocidental moderna. 
O controle das sexualidades "periféricas", no século XIX, provocou o surgimento de novas nomenclaturas cujo objetivo era o de marcar, estigmatizar os indivíduos. 0 surgimento da figura do/a "homossexual ${ }^{5 "}$ do século XIX merece destaque, pois o mesmo foi considerado como uma "espécie" e suas preferências por relações com o mesmo sexo, como uma doença e, como toda enfermidade, passível de tratamento.

A segregação imposta por uma ideia de sexualidade fora do padrão social forçou a uma organização lenta dos grupos homossexuais, sendo que a clandestinidade foi até a década de 1970, especialmente, no Brasil $^{6}$, a forma encontrada pelas pessoas com preferência homossexuais para efetivar reuniões, encontros e associações. As expressões culturais, representadas, sobretudo por artigos, revistas, obras de arte, poemas, músicas e jornais foram fundamentais na disseminação e na maior publicização da homossexualidade no âmbito internacional e nacional ${ }^{7}$. A formação do movimento político em defesa da homossexualidade no Brasil começa a florescer efetivamente no fim da década de 1970, com o fim do regime militar e a abertura política. Nesse momento, surgem os primeiros grupos articulando homens e mulheres homossexuais que deram o suporte para o delineamento futuro das lutas e conquistas na esfera pública. 0 debate e a constituição do movimento homossexual no Brasil acompa-

5 Foucault (1988) chama atenção para o fato de que "a categoria psicológica, psiquiátrica e médica da homossexualidade constituiu-se no dia em que foi caracterizada - o famoso artigo de Westphal em 1870, sobre as " sensações sexuais contrárias" pode servir de data natalícia” (FOUCAULT, 1988, p. 50).

6 Segundo Grossi (1998), os anos 60 foram um período de grande questionamento da sexualidade, no qual o sexo começou e ser pensado também como fonte de prazer, desvirtuando-se da ideia de reprodução humana.

7 Retornando ao período dos anos 1970, verifica-se que artistas como Ney Matogrosso, Caetano Veloso, dentre outros foram fundamentais na disseminação de novos papéis sócio-sexuais, na medida em que misturaram, brincaram, interconectaram e protagonizaram o feminino com o masculino, gerando polêmicas e confusões no imaginário da sociedade. As encenações performáticas de suas apresentações trouxeram elementos importantes para reflexão da sexualidade no Brasil. 
nharam as influências das ideias e das inquietações culturais e políticas que constituíam o cenário internacional, principalmente, os Estados Unidos e a França.

Essas concepções foram trazidas por intelectuais, principalmente os que se encontravam exilados e que contribuíam através das suas experiências com o questionamento acerca de problemas como o feminismo, a sexualidade, questões étnico-raciais e ambientais. De acordo com (FACCHINI, 2005), (RAMOS e CARRARA, 2006), o movimento homossexual brasileiro começou a se fortalecer a partir do surgimento do Grupo Somos, bem como, do jornal 0 Lampião da Esquina. Ambos no final da década de 1970 tiveram a presença marcante de intelectuais e figuras de destaque da sociedade brasileira que contribuíram para a disseminação e o fortalecimento do movimento homossexual (ALBUQUERQUE JUNIOR; CEBALLOS, 2005).

O movimento homossexual se fortaleceu e sua agenda de luta também incorporou novas dimensões que abarcam desde a defesa de uma integração à sociedade compreendendo esta como múltipla e diversa, a uma separação radical da sociedade, com a delimitação de uma comunidade e de uma cultura homossexual própria. Foi nesse momento que a percepção da importância de assumir a homossexualidade ${ }^{8}$ tornou-se imprescindível. 0 reconhecimento a partir dessa forma de identidade é crucial nesse momento histórico para a luta contra violências e contra as maneiras com que foram/são estereotipadas a figura do homossexual tornando-se, consequentemente, uma questão não só de cunho político, mas também pessoal, "Para fazer parte da co-

8 (FRY, 1982) e (GUIMARÃES, 2004) destacam que por volta do final da década de 1960, surge um novo sistema de classificação das identidades sexuais masculinas. Esse aparece entre a classe média do Rio de Janeiro e passa a ser denominado de "entendido", a discriminação/distinção entre os "homens" e "entendidos" passa a ser classificada a partir da orientação sexual. "O mundo masculino deixa de se dividir entre homens másculos e homens efeminados (...) e se divide entre "heterossexuais" e "homossexuais", entre "homens" e "entendidos." (GUIMARÃES, 2004, p. 94). 
munidade homossexual, seria indispensável que o indivíduo se 'assumisse', isto é, revelasse seu 'segredo', tornando pública sua condição (LOURO, 2001, p. 543).

Nos fim dos anos 1960 e na década de 1970, o Brasil vivenciava um momento marcado pela ditadura e por reivindicações em torno da redemocratização. 0 regime militar no Brasil iniciou-se em 1964, através de um golpe contra o então presidente da República João Goulart, assumindo logo, em seguida, o Marechal Castelo Branco. Tal regime durou entre 1964 e 1985 e foi presidido por cinco presidentes, que impuseram vários atos institucionais, inclusive o AI-5, o qual determinava a supressão das liberdades individuais.

Foi nesse contexto que alguns movimentos sociais começaram a se estruturar politicamente, organizar-se em grupos e a reivindicar pautas específicas de seus sujeitos. Assim aconteceu com os movimentos feminista, negro e homossexual, sendo que o movimento feminista antecedeu o movimento homossexual, e exerceu bastante influência sobre este último, segundo (PEDRO, 2005).

Os anos 1960 e 1970 são períodos bastante significativos no que tange às pré-condições de institucionalização do movimento homossexual no Brasil, marcando a mobilização organizada da busca de garantias de direitos por grupos homossexuais. 0 marco desse momento histórico ligou-se às mobilizações de maio de 1968, na França, e ao episódio de Stonewall ${ }^{9}$, que aconteceu nos Estados Unidos. No Brasil, o movimento iniciou-se sob a nomenclatura de "Movimento Homossexual". Essa definição muda com a passagem dos anos, principalmente, porque se estabelecem pautas de reivindicações específicas dos múltiplos sujeitos que brigam por direito a voz, dentro do próprio movimento homossexual, sendo definição do homossexual, enquanto sujeito político no cenário contemporâneo. 
nos dias atuais, designado como LGBT/LGBTTT (Lésbicas, Gays, Bissexuais, Travestis, Transexuais e Transgêneros) (FERNANDES, 2011; FROES DA SILVA, 2010, FRY, 1982, FACCHINI, 2005).

Sendo assim, ao longo dos anos, a sigla LGBT foi incorporada pelo movimento, e passou a substituir a denominação "Movimento Homossexual"10, mas o debate não se encerra, pois segundo Fernandes, "Não há ponto de unidade, nem na literatura nem no movimento sobre uma sigla que consiga encerrá-lo por completo, sendo que alguns grupos usam TTT (travestis, transexuais e transgênero)" (FERNANDES, 2011. p. 45). 0 autor ainda destaca que há grupos que propõem a inserção da sigla I (intersex) ou Q (Queer ou Questioning).

\section{H omofobia: um tema em evidência, uma categoria teórica recente}

O uso analítico da categoria homofobia requer a compreensão de que é algo recente na literatura científica, a construção de tal conceito está vinculada ao diálogo permanente entre academia, movimento social e políticas públicas. A incursão teórica para o entendimento da homofobia exige o percurso sobre os estudos de sexualidade com evidência ao importante papel desempenhado pelo movimento homossexual na luta por reconhecimento de direitos ao longo da história.

Para a definição do conceito de homofobia, buscou-se apoio teórico nos estudos de (BORRILLO, 2001), que o entende como um fenômeno complexo e variado que pode ser percebido através

10 Devido à maior visibilidade do movimento de mulheres lésbicas dentro do movimento homossexual, foi aprovada na 1ํㅡㄹ Conferência Nacional GLBT, ocorrida em Brasília no ano de 2008, a alteração do termo GLBT para LGBT. O objetivo reivindicado pelas mulheres era dar maior visibilidade às causas que envolvem as mulheres, especialmente as violências de gênero no contexto da diversidade sexual. A antecipação da letrinha "L" aconteceu em meio a grandes discussões. 
de piadas vulgares atingindo pessoas com preferências homoeróticas ou assumir formas mais brutais como a violência física ou o extermínio de homossexuais. A homofobia se exprime na vida cotidiana através de injúrias, insultos, violências, produções artísticas, científicas e nos debates públicos, instituições e principalmente na família.

Os/as pesquisadores/as (FERNANDES, GROSSI e PEDRO 2009), realizaram uma pesquisa junto à Plataforma Lattes ${ }^{11}$ no ano de 2008, com o objetivo de analisar a ocorrência da categoria homofobia em pesquisas acadêmicas brasileiras. Segundo os/as autores/as, essa categoria apresenta-se no cenário teórico atual como um tema emergente. Os campos de produção teórica sobre a temática ainda não produziram suficientemente "argumentos teóricos sobre a homofobia com o objetivo de subsidiar, seja as pesquisas acadêmicas sobre estas questões e sua atuação dentro da conjuntura sócio-histórica-política, seja os movimentos sócias LGBTTT" (FERNANDES; GROSSI; PEDRO, 2009, p. 1).

Outro dado relevante apontado pelos/as pesquisadores/as mostra que a entrada do termo homofobia nas pesquisas brasileiras se estabelece, sobretudo, através do movimento homossexual e das políticas públicas da última década, e não das pesquisas acadêmicas para o movimento. Esse fato demonstra a importância que o movimento e a formulação de políticas públicas têm para a consolidação do campo de estudos da homofobia. Por outro lado, (FERNANDES, 2011) chama atenção para o fato de que a homofobia se apresenta na atualidade como uma categoria híbrida entre o teórico e o político, "é usada no campo interdisciplinar dos estudos de gênero e estudos gays e lésbicos composto por uma coalizão movimentos Sociais-Estado-Universidade, cada segmento com papéis definidos" (FERNANDES, 2011, p. 66).

11 De acordo com os/as autores/as, a Plataforma Lattes é uma experiência do Conselho Nacional de Desenvolvimento Científico e Tecnológico (CNPq) para integração de bases de dados de currículos e de instituições acadêmicas brasileiras. 
A construção do conceito de homofobia esteve, portanto, ligada à teoria e às práticas políticas, sobretudo, através do movimento homossexual. A problematização do conceito foi fundamental para conquistas de alguns direitos nas últimas décadas, principalmente no campo do reconhecimento das múltiplas identidades, na luta por políticas de prevenção da AIDS ${ }^{12}$ e contra todas as formas de violências que acometem homossexuais. (FERNANDES, 2011) argumenta que, nos anos 2000, houve uma "explosão discursiva" em torno do conceito "homofobia" em curso nas agendas políticas e teóricas LGBTTT" (FERNANDES, 2011; FERNANDES; GROSSI; PEDRO, 2009).

Em virtude do surgimento recente desse conceito, o debate sobre homofobia enquanto categoria teórica analítica ainda está se constituindo. Além disso, destaca que os usos dessa categoria nos estudos acadêmicos, em sua maioria, está ligado à analise de pontos referentes às políticas públicas e aos movimentos sociais, à escola e aos materiais didáticos, às representações sociais sobre homofobia, aos aspectos jurídicos relacionados à legislação protetiva para homossexuais e sobre as violências e crimes de ódio, e em áreas como Educação, Psicologia, Antropologia e História (FERNANDES, 2011, p. 66).Nesse sentido, (FERNANDES, 2011, p. 68) propõe uma historicização do conceito de homofobia, destacando que existem ao menos "cinquenta anos de investimento político-teórico (1970-2010) que se inicia pela geração de Stonewall" (FERNANDES, 2011, p. 68).

A homofobia se define como formas de preconceito e violências que são utilizadas pela sociedade e instituições sociais contra a população homossexual. Termo pensado inicialmente a partir de uma perspectiva clínica e vinculado à ideia de doença motivada por pensamentos e atitudes negativos em relação aos homos-

12Termo que se refere à justaposição das siglas em inglês do vírus causador e da própria síndrome da imunodeficiência adquirida. Essa enfermidade destrói o sistema imunológico expondo o corpo a doenças oportunistas, conforme (SIMÕES e FACCHINI, 2009). 
sexuais. A partir dessa perspectiva, sentimentos como desprezo, ódio, aversão, nojo, medo eram associados a indícios ou sintomas de homofobia, e vinculadas também à repulsa relacionada às relações afetivas e sexuais entre pessoas do mesmo sexo.

Em função dos debates atuais e com o argumento contra a homogeneização das identidades gays, lésbicas e transexuais as discussões abarcam também os conceitos de lesbofobia e transfobia. A partir dessas explicações, postula-se a transferência da ideia de "fobia" associada até então a aspectos individuais, para a construção de categorias teóricas e políticas relacionadas à vertente cultural que abrange os preconceitos e o comportamento social e os movimentos sociais têm papel fundamental nesse processo.

Portanto, alarga-se a crítica a outros campos como o cultural, o educacional, o político, o institucional, o jurídico, o sociológico, o antropológico. Nessa perspectiva, a homofobia passa a ser compreendida como forma de restrição de direitos que abrange a educação, a saúde, o trabalho, a segurança e que envolve um jogo de relações de poder, na medida em que a construção de preconceitos e discriminações homofóbicas também está ligada ao campo de disputas em que são definidas socialmente as questões de masculinidades e feminilidades. (PRADO e JUNQUEIRA, 2011) destacam que, embora existam na atualidade, bastantes discussões sobre o uso do termo homofobia, ainda persistem vestígios dos discursos médico e clínicos, associando a homofobia a emoções negativas de cunho psicopatológico.

(BORRILLO, 2001, p.15) define a homofobia como "atitude de hostilidade para com os homossexuais". A homofobia se apresenta, principalmente, a partir da falta de reconhecimento, de compreensão, de respeito e tolerância em relação à manifestação do desejo erótico e do amor de uma pessoa por outra do mesmo sexo. Os códigos culturais e as estruturas sociais têm papel importante na consolidação de práticas homofóbicas, na medida em que reforçam a discriminação em relação às homossexualidades. (TEI- 
XEIRA FILHO et al., 2007) seguem a mesma linha de (BORRILLO, 2001) e definem a homofobia como qualquer sentimento que se estabelece a partir da manifestação do ódio, repulsa, aversão, descrédito ou desprezo à pessoa com preferência por práticas homoeróticas, manifestando-se através de violências variadas.

Borrillo (2001) chama atenção para o fato que a homofobia é uma maneira de inferiorização, consequência direta da hierarquização das sexualidades, que atribui à heterossexualidade um status superior, natural e normativo. A diferença heterossexual/homossexual se coloca de várias maneiras e tem a função de ordenar os modelos de sexualidades, nos quais os comportamentos relacionados ao padrão heterossexual são considerados os socialmente aceitáveis.

Uma das manifestações da homofobia se apresenta principalmente pelo receio de se ver ruir as fronteiras que delimitam a hierarquia da heterossexualidade. 0 sexismo, além de implicar na subordinação do feminino ao masculino, atua ainda na hierarquização da sexualidade, que é o fundamento da homofobia. O sexismo, portanto, pode ser compreendido como crença dispensada à ideia de uma hierarquia sexual, na qual a heterossexualidade é apresentada como o modelo social a ser seguido.

Welzer-Lang (2001) faz uma reflexão considerando que o heterossexismo e a homofobia têm ligações com a dominação masculina e parecem ser um produto de um duplo modelo naturalista que tem raízes na pseudo natureza superior dos homens e na visão heterossexuada do mundo. A ideia de uma natureza superior dos homens remete diretamente ao sexismo e também às "fronteiras rígidas e intransponíveis entre os gêneros masculino e feminino" (WELZER-LANG, 2001, p. 460). Dessa maneira, a definição de homofobia para (WELZER-LANG, 2001, p. 465) se traduz da seguinte forma "a discriminação contra as pessoas que mostram, ou a quem se atribui algumas qualidades (ou defeitos) atribuídos ao outro gênero. A homofobia engessa as fronteiras do gênero". 
Mott (2000), em um texto intitulado Por que os homossexuais são os mais odiados dentre todas as minorias, aponta dez razões para explicar os processos de discriminação que os gays, lésbicas, travestis e transexuais sofrem em nossa sociedade. Argumenta o autor que os homossexuais foram os mais odiados por que o amor entre pessoas do mesmo sexo em diferentes períodos da história foi considerado como pecado, crime, doenças e por causa disso, muitas vezes escondido. Esse é um fato que também contribuiu para o desenvolvimento do que denomina de homofobia internalizada por parte da sociedade, com manifestação e bastante repressão através de variados setores sociais e institucionais como a família, a escola, o ambiente de trabalho, a igreja, partidos políticos. A homofobia internalizada termina, muitas vezes, por contaminar as pessoas mais interessadas como os gays, as lésbicas, travestis, transexuais e transgêneros, que se escondem com vergonha dos próprios desejos, adoecem vítimas de uma autoestima baixa, cometem suicídio por não terem coragem de expor socialmente os seus desejos sexuais.

Outro ponto levantado pelo autor diz respeito à repressão familiar, que se constitui em um dos maiores fatores de exclusão da população homossexual. Em muitos casos, quando as famílias descobrem ter um/a filho/ gay, lésbica, travesti ou transexual terminam por reproduzir graves constrangimentos, violências psíquicas e físicas, insultos, tratamentos destinados à cura e até a judiciarização do relacionamento vivenciado por jovens menores de idade, a fim de que a justiça estabeleça e os convença de que a heterossexualidade é a melhor e mais correta norma a ser seguida, conforme destaca estudos de (COSTA, 2013). Apesar de maior tolerância com as diversas manifestações da sexualidade, os/as jovens que mantêm relações homoeróticas são frequentemente coagidos/as e constrangidos/as em relação à sua autonomia sexual. A família, o ambiente profissional e os/as amigos/ as constituem-se como os menos tolerantes com as experiências homoeróticas (SCHULMAN, 2010; PAIVA, 2009; NUNAN, 2007). 
Outro destaque a que o autor chama atenção é que as lutas em torno da homossexualidade durante muito tempo foram encaradas como algo menor por partidos políticos de esquerda e intelectuais. Fato esse que prejudicou muito o avanço em relação à conquista de direitos sociais fundamentais para o/a homossexual, essa luta só ganhou força a partir do final da década de 1970 no Brasil, fim do contexto de ditadura militar (GRENN, 2000). A homofobia acadêmica e a homofobia presente nos discursos de lideranças que se voltam para a defesa dos direitos humanos também são fatores graves que corroboram a tese de que os homossexuais são os mais excluídos dentre as minorias.

\section{C ombate à homofobia em Sergipe: a constituição de uma luta}

Como observado anteriormente, as condições de constituição da luta contra a homofobia se atrelaram ao reconhecimento das múltiplas identidades da população LGBTTT, as lutas por políticas de prevenção da AIDS e contra todas as formas de violências que acometem homossexuais. Em Sergipe, essa bandeira do movimento se constituiu de modo semelhante.

É possível identificar o surgimento do movimento homossexual em Sergipe no início da década de 1980 com a fundação do Grupo Dialogay $^{13}$, sendo reconhecido como um dos mais antigos do Brasil. Institucionalizou-se logo após o surgimento do Grupo Gay da Bahia, e teve desde o seu princípio apoio do professor Luiz Mott.

Outros grupos só começaram a surgir no Estado a partir do ano de 1998, Conforme destaca o Jornal Cinform: 
O grupo foi fundado em 1981 pelo auxiliar de escritório Wellington Andrade, 46, homossexual assumido desde os "20 e poucos anos". Seu objetivo era transformar em orgulho o que o status quo - muitas vezes hipocritamente - encarava como vergonha. As palavras-chave eram engajamento e militância. Wellington já começara a caminhar nesta direção no ano anterior - 1980 - quando trouxe para lançar em Aracaju o jornal baiano "Lampião da Esquina", direcionado ao público homossexual. 0 sociólogo Luiz Mott, presidente e fundador do então recém-nascido Grupo Gay da Bahia, obteve o endereço de Wellington na sede da publicação, veio a Aracaju e estimulou-o a agregar, também em Sergipe, os que praticavam amor entre iguais. Nascia o Dialogay, inicialmente com três mulheres e quatro homens (VITÓRIA..., 2001, p. 6).

Durante os anos 1980 e 1990, o Dialogay desenvolveu importantes mobilizações na cidade de Aracaju e no Estado sergipano em torno das causas homossexuais. Os pontos fortes de luta incluíam a violência contra homossexuais, a exigência de políticas públicas de prevenção à AIDS, o debate sobre união civil e luta incessante em prol do respeito à diversidade, o que levou o grupo a diversos posicionamentos públicos que fortaleceram a luta na cidade.

Conforme Wellington Andrade destacou em entrevista concedida, a criação do grupo faz parte de um projeto pessoal e subjetivo, pois a sua concepção esteve vinculada também aos preconceitos que sofreu por causa da sua sexualidade,

Quando eu fundei o grupo Dialogay em Aracaju em 1981, por aí (...) essa palavra "homofobia" não existia. (...) Eu apenas fundei, porque sou filho de famílias evangélicas (...) Nasci gay. Houve preconceitos com religião, com colégio, com a faculdade, com a família, com a vizinhança e com a sociedade. (...) Aí, a gente estava tentando acabar com o preconceito, com a discriminação que havia, que está havendo e sempre haverá com homossexuais (..). Então, naquela época, não se usava a 
palavra gay, lésbica, apenas homossexuais. Do meu trabalho humano e voluntário fundei este grupo e após a fundação deste grupo, foi quando sugiram a campanha de combate da AIDS. Onde nós lançamos o programa de combate a AIDS, pelo Dialogay, em 1983 (ANDRADE, 2010, Entrevista) ${ }^{14}$.

Na entrevista, Wellington destaca a inexistência da palavra homofobia na época de fundação do grupo, o que ratifica esta categoria teórica e política como recente, conforme já apontado por (FERNANDES, 2011), ao mesmo tempo, enfatiza o uso da palavra homossexual para referenciar pessoas com preferências afetivo-sexuais homoeróticas, demonstrando que a fragmentação das identidades é algo recente no movimento político nacional. Ressalta também que a fundação do grupo esteve vinculada às experiências pessoais que viveu, sobretudo às relacionadas ao preconceito familiar, religioso e na escola.

Mesmo com dificuldades no início, o grupo conseguiu articular muitas ações como conferências, eventos culturais, ciclo de palestras com temáticas diversificadas que incluíam homossexualidade, AIDS/DST's, campanhas contra assassinatos de gays, violência de gênero. Ao realizarem um balanço sobre as atividades desenvolvidas pelo grupo desde sua criação até o ano de 1983, numa carta direcionada "aos grupos, revistas, jornais e ativistas", contabilizou-se como realizações do grupo: um ciclo de conferências com o fundador do Grupo Gay da Bahia, um piquenique, cinco palestras e debates, cinco shows, o lançamento de um livro de poesias (de uma ativista baiana), seis peças de teatro e a participação no I Encontro Cultural de Aracaju (ANDRADE, 1983).

Os eixos de lutas travados pelo Dialogay estavam em consonância com o momento político vivenciado pelo movimento homossexual no Brasil. As denúncias de violências contra gays se fizeram muito presentes durante os anos 1980 e 1990, de acordo com

14 Entrevista concedida por Wellington Andrade em outubro de 2010 (ANDRADE, 2010). 
(RAMOS e CARRARA, 2006), desde o início tal temática pautou as mobilizações dos movimentos homossexuais por todo país.

A princípio preocupados com a questão da afirmação homossexual, as bandeiras de luta do movimento se firmavam na possibilidade de dar visibilidade à militância. "Assumir-se" era a palavra de ordem no início da década de 1980, na mobilização homossexual no Brasil e em países do hemisfério norte (MACRAE, 1982). Em Aracaju isso não era diferente, a utilização do "escândalo" e da "desmunhecação" comportamentos é confirmada por (ROSA, 2005) que aponta, no início da década de 1980, a utilização do slogan "É legal ser homossexual" pelo Dialogay como estratégia de valorização da "prática homossexual", com a "perspectiva de assumir-se em público, através de trejeitos, roupas e adereços, ou o simples ato de colocar um brinco na orelha, como uma espécie de transgressão e/ou ato de auto-afirmação" (p. 23). Dessa maneira, cunhava-se aquilo que deveria ser a "militância gay" em Aracaju e seus objetivos naquele momento.

Entretanto, a segunda metade da década de 1980 apresentou mudanças nos cenários mundial e brasileiro da mobilização homossexual, não só baseadas em reconfigurações políticas e ideológicas, mas principalmente, em função da epidemia do HIV/ AIDS que modificou as vidas dos homens gays, suas crenças sobre o sexo saudável, seu orgulho identitário e suas organizações políticas e culturais (ARMSTRONG, 2002).

Hoje se sabe que o HIV/AIDS não destruiu o movimento homossexual. Muito pelo contrário, a epidemia exigiu que o movimento se reestruturasse para sobreviver às mudanças suscitadas pela nova realidade. Em parte por causa dos estigmas relacionados à epidemia do HIV/AIDS e a todo o sofrimento causado, a epidemia foi profícua no que tange à produção, ao reforçamento e à visibilidade das identidades políticas homossexuais. (BOZON, 2004) afirma que o aparecimento do HIV/AIDS possibilitou que a preocupação médica com a sexualidade ultrapassasse "o campo da prática clínica para se ex- 
pressar no plano político, nacional e internacional" (BOZON, 2004, p. 148). Deste modo, as respostas brasileiras à epidemia apenas podem ser compreendidas levando-se em conta as relações internacionais com diferentes interlocutores "sejam conferências internacionais, publicações, universidades, agências de financiamentos ou institutos de pesquisa, entre outros" (GALVÃO, 2000, p. 36).

O cenário empolgante da "primeira onda do movimento homossexual", caracterizado pelo surgimento e o crescimento de instituições pelo Brasil, logo cedeu espaço a uma dispersão da mobilização. Dos poucos grupos "sobreviventes" daquele período, o Grupo Dialogay de Sergipe foi um deles e, em parte, sua manutenção se deve, naquele período, a um estreitamento das relações do grupo com o Estado em virtude do combate ao HIV/AIDS.

A primeira notificação de soropositividade em Sergipe, em $1987^{15}$, e a criação de um Programa Estadual DST/AIDS, no mesmo ano, tornaram estreitas as relações do Dialogay com a Secretaria de Saúde do Estado. No mesmo ano, a associação em conjunto com o Grupo Gay da Bahia, o BEMFAM (Bem-estar Familiar no Brasil) e o Movimento de Libertação Homossexual, realizaram o "1ํㅗㄹ Seminário sobre DST e AIDS no Estado de Sergipe" durante dois dias (GRUPO DIALOGAY DE SERGIPE, 1987).

O vínculo do grupo com a Secretaria de Saúde do Estado se tornou cada vez mais estreito através do médico sanitarista Almir Santana, que se tornou Coordenador Estadual do Programa de Combate ao HIV/AIDS, e que começara a realizar trabalhos de prevenção de Doenças Sexualmente Transmissíveis (DSTs) em bairros periféricos em Aracaju em 1985 e se notabilizou, com reconhecimento nacional, como um dos principais personagens no combate à AIDS. 
É possível notar também, na luta contra o HIV/AIDS, modificações nas "categorizações epidemiológicas" que, na década de 1980, classificavam os homossexuais como "grupo de risco", para uma ideia de "vulnerabilidade social" no final dos anos de 1980 e início de 1990. A vulnerabilidade, neste caso, está fundamentada na percepção de que a disseminação da epidemia se baseia em fatores como desigualdade, injustiça, preconceito, discriminação, opressão, exploração e violência dirigidas às vítimas acometidas pela doença (PARKER, 2000). Contudo, a concepção de "vulnerabilidade social" se estende também a outras "lutas", a exemplo do combate à "homofobia", onde se percebe a "vulnerabilidade social", aponta (SEFFNER, 2011, p. 44), como uma falta de proteção "diante de potenciais danos de saúde e ameaças à satisfação de suas necessidades básicas e seus direitos humanos".

Alterações também são perceptíveis nos "modelos interventivos de prevenção" ao HIV/AIDS, inicialmente baseados em informações e mudanças comportamentais, modificados para modelos de "transformação e justiça social", que enfatizam a "defesa dos direitos humanos" e o "enfrentamento das condições de opressão sexual e social” (PARKER, 1997; 2000; TERTO JR., 2002).

Deste modo, observa-se uma nova gramática que se estabeleceu entre o movimento e o Estado que, de certo modo, estreia um novo estatuto ontológico para a população homossexual, que passou a ser percebida como de sujeito de direitos. Este caminho abriu, inequivocamente, espaço para a construção, consolidação e institucionalização da bandeira contra a homofobia.

Embrionariamente, em Sergipe, durante a década de 1990 e sob a influência do Grupo Gay da Bahia, o Dialogay dava seus primeiros passos em relação ao combate da "violência anti-gay", com a divulgação de um número anual de "homossexuais assassinados" no Estado, como pode ser averiguado na constatação de (MELO, 2011): 
Em 1991, ao comemorar 10 anos de existência, o grupo realizou uma campanha acerca da existência de uma "Violência Anti-Gay" que permeava a sociedade sergipana. Assassinatos, espancamentos, agressões morais e até estupros, foram denunciados como recorrentes na capital do estado, principalmente durante a "vida noturna" dos "homossexuais", ou ainda, por seus "parceiros" (...)Um evento semelhante, denominado de "Dia de protesto contra a violência aos homossexuais", promovido pelo "Dialogay" e pelo "Grupo Gay da Bahia", parceria existente desde a criação da associação, viria a se repetir em 1992, com a inauguração da "Rua 28 de junho" ("Dia Internacional do Orgulho Gay") num bairro da zona sul da cidade. 0 fato, por si só, denota uma inserção política significativa da entidade (MELO, 2011, p. 6).

A década de 1990 foi muito representativa na capital sergipana no que se refere à quantidade expressiva de assassinatos cometidos contra homossexuais. Os casos ganharam repercussão em todo o Estado, e puseram em evidência as mudanças que afetam as famílias tradicionais, na medida em que expôs a situação de homossexuais "bem casados", profissionalmente bem sucedidos e com famílias estruturadas, mas que escondiam as preferências sexuais, e mantinham relações homossexuais fora do casamento, na maioria das vezes, indo ao encontro de garotos de programa. Casos como esses ao tempo em que foram expostos pelos jornais fomentando o debate sobre a sexualidade, também revelaram os aspectos conservadores que permeavam as matérias, na medida em que os meios de comunicação impressos apelavam para o sensacionalismo, contribuíram para despertar culturalmente a ideia de perigo que ronda as práticas sexuais que fogem à regra heterossexual.

As denúncias de violação aos direitos dos homossexuais, contudo, não se limitavam aos assassinatos, mas faziam referência também à proibição de doação de sangue por gays a partir da Portaria 1376/93 ou a proibição de participação do líder do Dialogay de participar de um bloco de carnaval da cidade por ser homossexual (ANDRADE, 1999), 
Na década seguinte, e com a participação de uma nova geração de militantes, alguns eventos apontam a aceitação e o apoio político local às reivindicações em torno do combate à homofobia: 1) a criação de "Centro de Atendimento a Grupos Vulneráveis"16, em 2003, com atendimento exclusivo a mulheres, crianças, adolescentes, e grupos vulneráveis (homossexuais, idosos, negros e indígenas) (DIREITOS..., 2011); 2) a aprovação, em 2007, na Câmara Municipal de Aracaju, de um projeto de lei que institui o dia "17 de maio" como "Dia municipal de combate á homofobia" (APROVADO..., 2007; ARACAJU..., 2007); 3) a criação em 2008, numa articulação entre a Secretaria de Segurança Pública do Estado e a militância local, de um "Centro de Combate à Homofobia".

A criação deste centro foi um marco para as políticas públicas e para os LGBTTT. 0 centro é responsável pelo atendimento jurídico, acolhimento pessoal e promoção dos Direitos da Cidadania da comunidade. A iniciativa é resultante de um convênio entre o governo do Estado de Sergipe e o governo federal, por meio da Secretaria Nacional de Direitos Humanos. A unidade que disponibiliza uma equipe multidisciplinar composta por psicólogos, pedagogos e advogados orientados para dar apoio e assistência aos usuários, também conta com a parceria do Ministério Público, Defensoria Pública, Tribunal de Justiça, Ordem dos Advogados do Brasil (OAB), das universidades e outras secretarias envolvidas com o projeto.

Não obstante a importância do centro como resultante de uma articulação entre as demandas da mobilização e uma resposta do Estado como fomentador de políticas públicas, o funcionamento desta instituição é um ponto melindroso na relação entre estas duas esferas políticas. Se por um lado o Estado atendeu às solicitações da mobilização ao constituir um espaço de combate ao "flagelo da violência" experimentado pelos LGBTTT, por outro lado, o mesmo movimento não reconhece a legitimidade da instituição por esta não ter à sua frente os agentes da mobilização. Segundo (MELO, 2013), 
em vários momentos da pesquisa que realizou, através de escuta atenta em eventos, reuniões ordinárias e debates informais, foi possível perceber a insatisfação de algumas lideranças que apontavam o fato da militância ter sido preterida na gestão do centro e de estarem à sua frente pessoas com cargos comissionados que não eram LGBTTT e desconheciam os problemas existentes.

É evidente que tais investimentos públicos foram possíveis por causa das pressões dos movimentos sociais e também do posicionamento de alguns atores políticos importantes que defendem a causa homossexual e investiram na criação de instituições que atenuassem as violências sofridas pelos homossexuais, entre eles destacamos o delegado de polícia Mário Leony, um dos protagonistas na implantação do Centro de Combate à Homofobia em Sergipe. A participação deste agente no combate à homofobia reforça a percepção da existência de um imbricamento entre a mobilização e o Estado.

Ressalta-se que há uma tendência teórica, ao menos na seara dos debates sobre as mobilizações políticas, em separar em blocos distintos movimentos sociais e Estados, fato que impossibilita reconhecer o entrecruzamento das fronteiras dos campos. Contudo, algumas pesquisas conduzidas no Brasil de (SEIDL, 2009), (OLIVEIRA, 2007a; 2007b) e (REIS, 2007) não negligenciaram este aspecto em suas análises. Seus estudos observaram este tipo de imbricamento em distintos movimentos no Brasil, em períodos históricos que variam entre as décadas de 1960 e 2000. As trajetórias dos agentes engajados nos movimentos negro, ambiental e estudantil, entrelaçam-se com os partidos políticos e às esferas legislativas e administrativas do governo.

Em comparação ao movimento negro em Sergipe, as análises de (SOUZA, 2012) apresentam, guardadas as diferenças e alcances das mobilizações, a existência de semelhanças com o movimento LGBTTT no que tange as articulações com o Estado e a prefeitura de Aracaju que lhes possibilitaram o atendimento de suas agendas políticas, "a emergência de órgãos públicos de combate ao racismo e 
a reconversão de recursos oriundos dos itinerários individuais em cargos públicos nestes órgãos e outros" (SOUZA, 2012, p. 113). Isso se torna mais evidente ao serem observados os órgãos e políticas públicas criados, desde a década de 1980, para o atendimento de homossexuais e LGBTTT nos setores de "combate ao HIV/AIDS" e "combate à homofobia", dispostos na tabela abaixo:

Tabela 1 - Órgãos/Programas voltados para a criação e execução de políticas públicas pata a população homossexual e LGBTTT

\begin{tabular}{|c|c|c|c|c|}
\hline Órgão & $\begin{array}{l}\text { Ano de } \\
\text { criação }\end{array}$ & $\begin{array}{l}\text { Esfera de } \\
\text { atuação }\end{array}$ & Governo & Atividade \\
\hline $\begin{array}{l}\text { Departamento Nacional } \\
\text { de DST/AIDS }\end{array}$ & 1986 & Federal & PMDB & $\begin{array}{l}\text { Formula e fomenta políticas } \\
\text { públicas de DST, Aids e hepa- } \\
\text { tites virais em nível federal }\end{array}$ \\
\hline $\begin{array}{l}\text { Gerência Estadual DST/ } \\
\text { AIDS }\end{array}$ & 1987 & Estadual & PFL & $\begin{array}{l}\text { Fomenta e executa ações de } \\
\text { políticas públicas de DST, Aids } \\
\text { e hepatites virais em nível es- } \\
\text { tadual }\end{array}$ \\
\hline $\begin{array}{l}\text { Delegacia Especial de } \\
\text { Proteção à Mulher }\end{array}$ & 1996 & Estadual & PSDB & $\begin{array}{l}\text { Atendimento às vítimas e in- } \\
\text { vestigação de crimes contra } \\
\text { os LGBTTT. }\end{array}$ \\
\hline $\begin{array}{l}\text { Coordenação Municipal } \\
\text { de DST/AIDS e Hepa- } \\
\text { tites Virais }\end{array}$ & 1999 & $\begin{array}{l}\text { Municipal } \\
\text { (Aracaju) }\end{array}$ & PMDB & $\begin{array}{l}\text { Fomenta e executa ações de } \\
\text { políticas públicas de DST, Aids } \\
\text { e hepatites virais em nível } \\
\text { municipal }\end{array}$ \\
\hline $\begin{array}{l}\text { Delegacia Especial de } \\
\text { Atendimento a Grupos } \\
\text { Vulneráveis (DAGV) } \\
\end{array}$ & 2004 & Estadual & PFL & $\begin{array}{l}\text { Atendimento às vítimas e in- } \\
\text { vestigação de crimes contra } \\
\text { os LGBTTT. }\end{array}$ \\
\hline $\begin{array}{l}\text { Programa Brasil Sem } \\
\text { Homofobia (Secretaria } \\
\text { de Direitos Humanos) }\end{array}$ & 2004 & Federal & PT & $\begin{array}{l}\text { Apoio a projetos, formação e } \\
\text { capacitação profissional na } \\
\text { temática de direitos humanos } \\
\text { da população LGBTTT. }\end{array}$ \\
\hline $\begin{array}{l}\text { Centro de Referência } \\
\text { em Direitos Humanos e } \\
\text { Combate à Homofobia }\end{array}$ & 2008 & Estadual & PT & $\begin{array}{l}\text { Acolhimento e atendimento } \\
\text { jurídico e psicossocial, além } \\
\text { de promover os Direitos da } \\
\text { Cidadania do público LGBTTT. }\end{array}$ \\
\hline $\begin{array}{l}\text { Núcleo de Atendimento } \\
\text { à Diversidade Sexual }\end{array}$ & 2013 & $\begin{array}{l}\text { Municipal } \\
\text { (Estância) }\end{array}$ & DEM & $\begin{array}{l}\text { Desenvolve ações sociais de } \\
\text { inclusão e proteção à cidada- } \\
\text { nia e contra a discriminação e } \\
\text { violência aosLGBTTT. }\end{array}$ \\
\hline
\end{tabular}

Fonte: (MELO, 2013, p. 128-129) 
Perante este quadro, é inequívoco reconhecer que o pioneirismo do Grupo Dialogay de Sergipe foi importante e necessário, em função do trabalho desenvolvido, de suas relações com as instâncias estatais, das repercussões midiáticas com assuntos variados, opiniões esclarecedoras e progressistas, e certamente contribuiu para o surgimento de outros grupos e fortalecimento dos movimentos homossexual e LGBTTT em todo o Estado sergipano. Conforme (MELO, 2008, p. 77), em levantamento realizado junto ao Centro de Referência de Prevenção e Combate à Homofobia, à Associação Brasileira de Gays, Lésbicas, Bissexuais, Travestis e Transgêneros (ABGLT) e ao Grupo Gay da Bahia (GGB), foram identificadas oito associações LGBTTT na capital Aracaju, dedicando-se quatro delas ao trabalho exclusivo com a população homossexual masculino (Grupo Adhons, Grupo Diversidade de Sergipe, Grupo Homossexual do Bugio e Grupo Axé Kizomba), uma com travestis (Associação de Travestis Unidas), duas com lésbicas (Grupo Athena de Sergipe e Movimento de Lésbicas de Sergipe (MOLS) e apenas uma instituição que trabalha com todos os segmentos (Grupo ASTRA).

O movimento também ganhou espaço no interior sergipano onde foram registrados mais doze grupos: Gatho (Lagarto), Associação de Transgêneros de Lagarto (ASTRAL), Associação Sergipana de Transgêneros Estanciana (ASTRAES), Associação Gay Simãodiense (Simão Dias), Grupo Arco Íris (Salgado), Grupo Flor De Lís (Lagarto), Grupo Juventude Sempre Alerta (Boquim), Velha Casa GLBT (São Cristóvão), Associação Comunitária Igualdade (Tobias Barreto), Grupo Homo-Cidadã (Itaporanga), Grupo Lésbico de Lagarto (Lagarto) e a Associação GLBT Flor do Sertão (Poço Verde) (MELO, 2008, p. 77). 0 aumento da quantidade de grupos nos últimos vinte anos é bem representativo e o processo de interiorização desses grupos também chama a atenção. Talvez isso esteja vinculado ao que (FACCHINI, 2005) pontuou em seu livro, sobre a produção das identidades coletivas no movimento homossexual, pois se percebe a variação dos objetivos propostos pelas associações de acordo com o segmento que re- 
presenta (homossexuais masculinos, travestis, transgêneros e lésbicas) e a disseminação do debate pelo interior do Estado.

\section{C onclusões}

O debate em torno da homofobia esteve presente durante todo o processo de constituição do movimento homossexual em Sergipe. Evidentemente, as ações do movimento colocavam em pauta as diversas violências que atingiam a população LGBTTT, desde a década de 1980. A institucionalização do Dialogay e sua presença constante na mídia e nos espaços públicos com posicionamentos sobre direitos dos homossexuais, informações sobre AIDS, luta por políticas públicas e contra violências colocaram em evidência a fluidez das relações sexuais e da família, solicitando um posicionamento do Estado frente aos debates.

Um fato que chama atenção no Estado de Sergipe é a importância da ação individual de algumas pessoas para a formação de uma mentalidade coletiva e de políticas públicas. Esse fato aconteceu no campo da saúde, especialmente da luta contra a AIDS, no campo da segurança pública, com o estabelecimento de órgãos voltados ao combate à homofobia, e na esfera da militância, através da institucionalização do Dialogay. Foi através de tais ações que a população sergipana contou com um grupo homossexual forte nos anos 1990, destacou-se nas políticas de AIDS e segurança pública e propiciou o debate intenso sobre sexualidade e preconceito.

Vale lembrar que a década de 1990 se constituiu nacionalmente como um período de fortalecimento do movimento homossexual, na busca das garantias de direitos, onde a parceria com o Estado contribuiu para a multiplicação de grupos ativistas, manifestação dos diversos sujeitos do movimento, através do fortalecimento dos encontros nacionais de gays e lésbicas, e a consolidação de festas e espaços destinados ao segmento ho- 
mossexual, ações que tinham, inicialmente, o propósito de consolidar momentos de reivindicação e de lutas.

A efervescência das discussões envolvendo a homossexualidade fazia parte do contexto da época, e contribuía para o fortalecimento do movimento homossexual sergipano. Este teve um papel fundamental de atuação em várias frentes. Uma delas foi chamar a atenção da população para os elevados índices de assassinatos de gays, e levantar a bandeira contra a homofobia.

As formulações de políticas públicas no campo das doenças sexualmente transmissíveis, principalmente no que diz respeito à AIDS, foi um divisor de águas para a compreensão da homossexualidade no Estado, e estabeleceu um diálogo profícuo entre entidades estatais, ONG's e militância. 0 debate sobre AIDS ultrapassou as fronteiras da saúde pública, e proporcionou a necessidade da discussão sobre sexualidade, provocando o questionamento sobre as "certezas", e colocando em evidência a fluidez das relações sexuais, familiares e identitárias, ocasionando também a diversificação do movimento LGBTTT no interior do estado e o levante de outras pautas que dialogam com o contexto atual.

\section{REFERÊN CIAS BIBLIO GRÁFICAS}

ALBUQUERQUE JÚNIOR, Durval. M; CEBALLOS, Rodrigo. As várias dimensões do masculino: traçando itinerários possíveis. Revista de Estudos Feministas. v. 13, n. 1. Florianópolis, jan.-abr. 2005.

ANDRADE, Wellington [Carta]. Jan. 1983, Aracaju [para] Grupos, revistas, jornais, ativistas gays do Brasil e de outro país, s/n. 1f. Aniversário de dois anos do Grupo Dialogay.

ANDRADE, Wellington. Entrevista. Aracaju, out. 2010.

APROVADO projeto que institui dia municipal contra homofobia. Portal infonet, Aracaju, 29 jun. 2007. Disponível em: http://www.infonet.com.br/cidade/ler.asp?id=61215\&titulo=cidade. Acesso em 01 de junho de 2011. 
ARACAJU terá dia contra a homofobia, Jornal da Cidade, Aracaju, 30 de junho de 2007.

ARMSTRONG, Elizabeth. Forging gay identities: organizing sexuality in San Francisco, 1950-1994. Chicago: The University of Chicago Press, 2002.

BORRILLO, Daniel. Homofobia. Espanha: Bellaterra, 2001.

BOZON, Michel. Sociologia da sexualidade. Rio de Janeiro: Editora FGV, 2004.

CASTRO, Celso. Pesquisando em arquivos. Rio de Janeiro: Jorge Zahar Editor, 2008.

COSTA, Patricia R. S. M. Aracaju dos anos 90: Crimes Sexuais, Homossexualidade, Homofobia e Justiça, 2012. Tese de Dourado. Programa de Pós-Graduação Interdisciplinar em Ciências Humanas. Universidade Federal de Santa Catarina-UFSC, Florianópolis, 2013.

DIREITOS das sergipanas são garantidos na Delegacia da Mulher. Agência Sergipe de Notícias, Aracaju, 22 de mar. 2011. Disponível em http://www. agencia.se.gov.br/reportagens/leitura/materia:22071/direitos_das sergipanas sao garantidos na delegacia da mulher.html. Acesso em 01 de junho de 2011.

FACCHINI, Regina. Sopa de letrinhas? Movimento homossexual e produção de identidades coletivas nos anos 90. Rio de Janeiro: Garamond, p.304. (Sexualidade, gênero e sociedade, v. 6), 2005.

FERNANDES, Felipe B. M; PEDRO, Joana M; GROSSI, Miriam P. Homofobia como uma categoria teórica no Brasil (2008): notas preliminares sobre a produção de trabalhos de conclusão de curso, dissertações e teses a partir da pesquisa na plataforma Lattes In: SEMINÁRIO CORPO, GÊNERO E SEXUALIDADE,3., 2008. Rio Grande, Anais.(S.1.): FURG/RS, 2009, f.1.12.

FERNANDES, Felipe B. M. A Agenda Anti-Homofobia na Educação Brasileira (2003-2010). Florianópolis. Tese (Doutorado em Ciências Humanas) - UFSC, 2011.

FOUCAULT, Michel. Eu Pierre Rivière, que degolei minha mãe, minha irmã e meu irmão... um caso de parricídio do século XIX. Rio de Janeiro: Edições Graal, 1977.

FOUCAULT, Michel. História da sexualidade I: A vontade de saber. Rio de Janeiro: Edições Graal, 1988.

FRY, Peter. Para Inglês ver: identidade e política na cultura brasileira. Rio de Janeiro: Zahar editores, 1982.

FROES DA SILVA, Anelise. Mulheres em movimento(s): Estudo etnográfico sobre 
a inserção de feministas e lésbicas em movimentos sociais institucionalizados e autônomos na cidade de Porto Alegre/RS”. Dissertação (Mestrado em Antropologia Social)- Universidade Federal de Santa Catarina, 2010a. Disponível em: http:// www.tede.ufsc.br/teses/PASO0260-D.pdf, Acessado em: 02 fev. 2011.

GALVÃO, Jane. AIDS no Brasil: a agenda de construção de uma epidemia. Rio de Janeiro: Editora 34, 2000.

GREEN, James. N. A homossexualidade masculina no Brasil do século XX. São Paulo: Editora UNESP, 2000.

GRENN, James. Além do carnaval. A homossexualidade masculina no Brasil do século XX. São Paulo: Editora UNESP, 2000.

GROSSI, Miriam Pillar. Rimando amor e dor: reflexões sobre a violência no vínculo afetivo-conjugal. In: PEDRO, Joana. M; GROSSI, Miriam. P. (Org.). Masculino, feminino, plural: gênero na interdisciplinaridade. Florianópolis: Editora Mulheres, 1998, p. 293-313.

GRUPO DIALOGAY DE SERGIPE. Aracaju. Ata de registro do “1 Seminário sobre DST e AIDS no Estado de Sergipe" realizado no dias 25 e 26 de fevereiro de 1987. Livro de Ata 1. p. 29.

GUIMARÃES. Carmen Dora. O homossexual visto por entendidos. Rio de Janeiro: Editora Garamound, 2004.

LOURO, Guacira. L. Os Estudos feministas, os estudos gays e lésbicos e a teoria Queer como políticas de conhecimento. In: LOPES D.; BENTO, B.; ABOUD, S; GARCIA, W. (Orgs.), Imagem e diversidade sexual: Estudos da homocultura. São Paulo: Novas Edições, 2001. p 23-28.

MACRAE, Edward. Os respeitáveis militantes e as bichas loucas. In: MACRAE, Edward et al (org.). Caminhos cruzados: linguagem, antropologia e ciências naturais. São Paulo: Editora Brasiliense, 1982. p. 99-111.

MELO, Marcos Ribeiro de. Itinerários e "lutas": o engajamento de lideranças dos movimentos homossexual e LGBT em Sergipe (1981-2012). 2013. $226 f$. Tese (Doutorado em Sociologia) - Programa de Pós-graduação em Sociologia, Universidade Federal de Sergipe, São Cristóvão.

MOTT, Luiz. Por que os homossexuais são os mais odiados dentre todas as minorias? In: Seminário Gênero \& Cidadania: Tolerância e Distribuição da Justiça. Núcleo de Estudos de Gênero, Pagu, Unicamp, 6-12-2000. Disponível em: http://www.ifch.unicamp.br/pagu/sites/www.ifch.unicamp.br.pagu/files/ colenc.01.a09.pdf. Acessado em: 16 nov. 2010.

NUNAN, Adriana. Influência do preconceito internalizado na conjugalidade homossexual masculina. In: GROSSI, Miriam Pillar; UZIEL, Ana Paula; MELLO, 
Luiz ( Orgs.). Conjugalidades, parentalidades e identidades lésbicas, gays e travestis. Rio de Janeiro: Garamond, 2007.

PAIVA, A. C. S. Miséria de posição e o laço social nas homossexualidades. In: TORNQUIST, Carmem Suzana et al. (Orgs.). Leituras de resistência: corpo, violência e poder. v. I. Florianópolis: Ed. Mulheres, 2009. p. 216-242.

PEDRO, Joana Maria. Traduzindo o debate: o uso da categoria gênero na pesquisa histórica. História, São Paulo, v. 24, n.1. p.77-98, 2005.

PRADO, Marco. A. M; JUNQUEIRA, Rogério. D. Homofobia, Hierarquização e Humilhação Social. In: VENTURI, Gustavo; BOKANY, Vilma (Orgs.). Diversidade Sexual e Homofobia no Brasil. São Paulo: Editora Fundação Perseu Abramo, 2011.

OLIVEIRA, Wilson José Ferreira de. Posições de classe, redes sociais e carreiras militantes no estudo dos movimentos sociais. Anais II Seminário Nacional "Movimentos Sociais, Participação e Democracia”. Florianópolis, 2007a. p. 670-690.

Formas precárias de emprego, atuação em ONGs e inserção profissional. Sociedade em Debate, v. 12, n. 3. p. 141-160, 2007b.

PARKER, Richard. Reflexões sobre a sexualidade na sociedade latino-americana: implicações para intervenções em face do HIV/AIDS. PHYSYS: Revista de Saúde Coletiva, Rio de Janeiro, 7(1), 199., p. 99-108.

Na contramão da AIDS: sexualidade, intervenção, política. Rio de Janeiro: Editora 34, 2000.

RAMOS, Silvia; CARRARA, Sérgio. A constituição da problemática da violência contra homossexuais: a articulação entre ativismo e academia na elaboração de políticas públicas. PHYSIS: Revista de Saúde Coletiva, Rio de Janeiro, 16(2), 2006, p.185-205.

REIS, Eliana Tavares dos. Contestação, engajamento e militantismo: da "luta contra a ditadura" à diversificação das modalidades de intervenção política no Rio Grande do Sul. 2007. 464f. Programa de Pós-Graduação em Ciência Política, Universidade Federal do Rio Grande do Sul, Porto Alegre.

REZENDE JUNIOR, José. A peleja do Doutor Camisinha contra a aids e o preconceito.Disponível em: http://sistemas.aids.gov.br/blogvidas/. Acesso em 13 de julho de 2010.

ROSA, Gilvan dos Santos. Terceiro Setor: um estudo no Grupo Dialogay de Sergipe. Aracaju: Universidade Tiradentes, 2005. (monografia de Especialização no Terceiro Setor e Políticas Públicas).

SCHULMAN. Sarah. Homofobia familiar: uma experiência em busca de reconhecimento. Revista Bagoas. Natal. n. 5, 2010. p. 67-78. 
SEFFNER, Fernando. Identidade de gênero, orientação sexual e vulnerabilidade social: pensando algumas situações brasileiras. In: VENTURI, Gustavo; BOKANY, Vilma. Diversidade sexual e homofobia no Brasil. São Paulo: Editora Perseu Abramo, 2011. p. 39-50.

SEIDL, Ernesto. Disposições a militar e lógicas de investimento militantes. Pro-posições, Campinas, v.20, n.2 (59), maio/ago. 2009. p.21-39.

SIMÕES, Júlio Assis; FACCHINI, Regina. Do movimento homossexual ao LGBT. São Paulo: Editora Fundação Perseu Abramo, 2009.

SOUZA, Maria Erica Santana. Movimento negro em Sergipe e política institucional: um estudo a partir de carreiras de militantes negros. 2012.179f. Dissertação (Mestrado em Sociologia), Núcleo de Pós-Graduação e Pesquisa em Ciências Sociais, Universidade Federal de Sergipe, São Cristóvão.

TERTO JR., Veriano. Homossexualidade e saúde: desafios para a terceira década de epidemia do HIV/Aids. Horizontes Antropológicos, Porto Alegre, ano 8, n.17, 2002. p.147-158

TEXEIRA FILHO, Fernando. S. et al. A homofobia na representação de mães heterossexuais sobre a homoparentalidade. In: GROSSI Miriam Pillar; UZIEL Ana Paula; MELLO Luiz (Orgs). Conjugalidades, parentalidades e identidades lésbicas, gays e travestis. Rio de Janeiro: Garamond, 2007.

VITÓRIA contra o preconceito. Cinform, Aracaju-Sergipe, 12 a 18 de março de 2001, Ano XIX, n. 935. p. 6.

WELZER-LANG, Daniel. A construção do masculino: dominação das mulheres e homofobia. Revista Estudos Feministas, v 9, n.2, Florianópolis, 2001.

Data de Recebimento: 12 de dezembro de 2014

Data de Aprovação: 30 de dezembro de 2014 